PULMONARY EMBOLISM

\title{
Admissions for pulmonary embolism at a tertiary South African hospital
}

Sivaisen Ricardo Kistensamy*, Susan Brown" and Yoshan Moodley"

\section{"Department of Internal Medicine, Nelson R. Mandela School of Medicine, University of KwaZulu-Natal, Durban, South Africa "Department of Anaesthetics, Nelson R. Mandela School of Medicine, University of KwaZulu-Natal, Durban, South Africa}

\section{Address for correspondence:}

Sivaisen Ricardo Kistensamy

Department of Internal Medicine

Nelson R. Mandela School of Medicine

University of KwaZulu-Natal

719 Umbilo Road

Congella

Durban

4013

South Africa

Email:

drrickist@yahoo.com

\section{INTRODUCTION}

Pulmonary embolism (PE) is an important complication of deep vein thrombosis (DVT).(1) Both PE and DVT are manifestations of venous thromboembolism (VTE). An incidence rate of nearly 1.0 case per 1000 people has been reported for PE in North American/European settings.(2) Mortality is much higher in patients with undiagnosed, untreated PE.(3) Therefore, a better understanding of the presentation of $\mathrm{PE}$ is required, such that patients can be diagnosed timeously and treatment can be initiated. ${ }^{(4)}$ However, the presentation of PE itself is highly variable and can pose diagnostic challenges. ${ }^{(2,4,5)}$ While there are no specific data available for PE in a South African (SA) setting, a 2007 report found 2566 deaths in the country could be attributed to diseases of the circulatory system - a composite measure that includes $\mathrm{PE}$, stroke, and myocardial infarction. ${ }^{(6)}$ Interestingly, embolic pathophysiology also appears to play some role in stroke and myocardial infarction. ${ }^{(7,8)}$ While descriptions of PE in SA settings are rare, recent evidence from a study of DVT in a SA setting suggests that there might be some setting-specific differences in the characteristics and risk factors for VTE between SA and overseas settings. ${ }^{(9)}$ It is possible that there might be some discordance between the characteristics, risk factors, and mortality associated with PE between SA settings and overseas settings. However, this is yet

\section{ABSTRACT}

Background: Published reports of pulmonary embolism (PE) from South African (SA) settings are rare. We sought to address this paucity in the literature. Methods: This case series (CS) involved $6 \mathrm{I}$ adult patients admitted to a tertiary SA hospital over a five-year period with a primary diagnosis of PE. Data related to patient demographics, PE presentation, risk factors, treatment, and inpatient mortality were collected, and then analysed using descriptive statistics.

Results: Most of our CS were aged $<65$ years $(86.9 \%)$, female (67.2\%), and of black African ethnicity (73.8\%). Dyspnoea and chest pain were the most common symptoms ( $86.9 \%$ and $41.0 \%$, respectively). Common clinical signs included tachypnea (47.5\%) and tachycardia (42.6\%). Common established risk factors were cardiac failure (49.2\%) and obesity (27.9\%). Massive, submassive, and minor PE, was diagnosed in $8.2 \%, 62.3 \%$, and $8.2 \%$ of patients, respectively. Most patients received anticoagulation therapy (95.1\%), with thrombolysis and embolectomy performed only in smaller proportions (24.6\% and II.5\%) of patients. Inpatient mortality was 23.0\%. Most patients who died had submassive PE. Conclusion: We provide a report of PE cases from a SA setting. Our findings have important implications related to the management of PE in SA.

SAHeart 2018;15:196-200

to be demonstrated. A better description of PE in a SA setting would be useful in efforts to improve patient management and subsequent patient outcomes in this setting. Therefore, the aim of this research was to improve the current understanding of PE in a SA setting. The objectives of this research were to: (I) Determine the most common presenting characteristics of PE in patients who were admitted to a tertiary SA hospital with the condition (the case series - CS); (2) determine the inpatient mortality in the CS; and (3) discuss similarities and differences related to PE between SA and overseas settings.

\section{MATERIALS AND METHODS}

Research design, setting, and patients

This was a CS of adult patients who were admitted with a primary diagnosis of PE to the tertiary-level Inkosi Albert Luthuli Central Hospital (IALCH) in Durban, SA, over a 5-year period ( I January 20 I I - 3I December 20 I5). The population served by IALCH is predominantly of black African ethnicity. The 
hospital is situated in a SA province with a high HIV prevalence. The patients were identified using the hospital admissions database and the International Classification of Diseases 10th Revision (ICD-10) code 126 (includes 126.0, 126.9, and subcategories thereof). Furthermore, PE was confirmed through review of patient computed tomography reports. Patients aged $<18$ years, repeat admissions for $\mathrm{PE}$, existing inpatients at $I A L C H$, and patients admitted outside the specified period, were excluded from this research.

\section{Data collection}

The medical records of all patients included in this research were reviewed, and information related to patient demographics, clinical presentation, potential risk factors, classification and treatment of PE, and inpatient mortality, was collected using a paper-based data collection tool. Massive PE was defined as PE with haemodynamic instability. Submassive PE was defined as PE with haemodynamic stability and evidence of right ventricular dysfunction (as per echocardiogram) or myocardial necrosis (elevated troponin).(10) Minor PE was defined as PE that did not satisfy the criteria for the massive or submassive categories. All data were transferred to an electronic spreadsheet in preparation for statistical analyses.

\section{Statistical analysis}

We analysed our data using descriptive statistical methods. Results for the descriptive statistical analysis are presented as medians and interquartile range (IQR), or frequencies and percentages. We calculated the proportion of cases with inpatient mortality, and present this as a percentage with a 95\% confidence interval $(95 \% \mathrm{Cl})$. All statistical analyses were performed using the Statistical Package for the Social Sciences version 24.0 (IBM Corp, USA).
Ethical approval

This research received ethical approval from the University of KwaZulu-Natal Biomedical Research Ethics Committee (BE595/I6, BE589/17).

\section{RESULTS}

The final CS comprised 61 patients. A description of the CS is provided in Table I. The median age of the CS was 48.0 (IQR: 38.8 - 57.5) years old. Other important demographic observations included a preponderance of female cases and cases of black African ancestry. Dyspnoea and chest pain were the most common clinical symptoms. Tachypnea and tachycardia were the most common clinical signs. One in every 12 cases presented with haemodynamic instability. Half of all cases presented with elevated d-dimers measurements, while elevated troponin was observed in almost one-quarter of cases. The most common PE risk factors were cardiac failure, obesity, and current DVT. Most cases (almost two-thirds of cases) presented with submassive PE. Anticoagulation was the first choice treatment option, followed by thrombolysis and embolectomy.

Figure I shows the inpatient survival outcomes of the CS. Of the 61 patients in the CS, I 4 suffered inpatient mortality $(23.0 \%$, $95 \% \mathrm{Cl}: 13.2-35.5 \%)$. Of the 14 patients who suffered inpatient mortality, 3 patients had massive PE, 8 patients had submassive $P E$, no patients had a minor PE, and the PE could not be classified in the remaining 3 patients. Of the patients who died, most were aged $<65$ years old $(12 / 14,85.7 \%)$, female ( $12 / 14$, $85.7 \%)$, and of black African ethnicity ( $9 / / 4,64.3 \%)$. Dyspnoea and chest pain were the most common presenting symptoms in those who died, and were reported in 11/14 (78.6\%) and

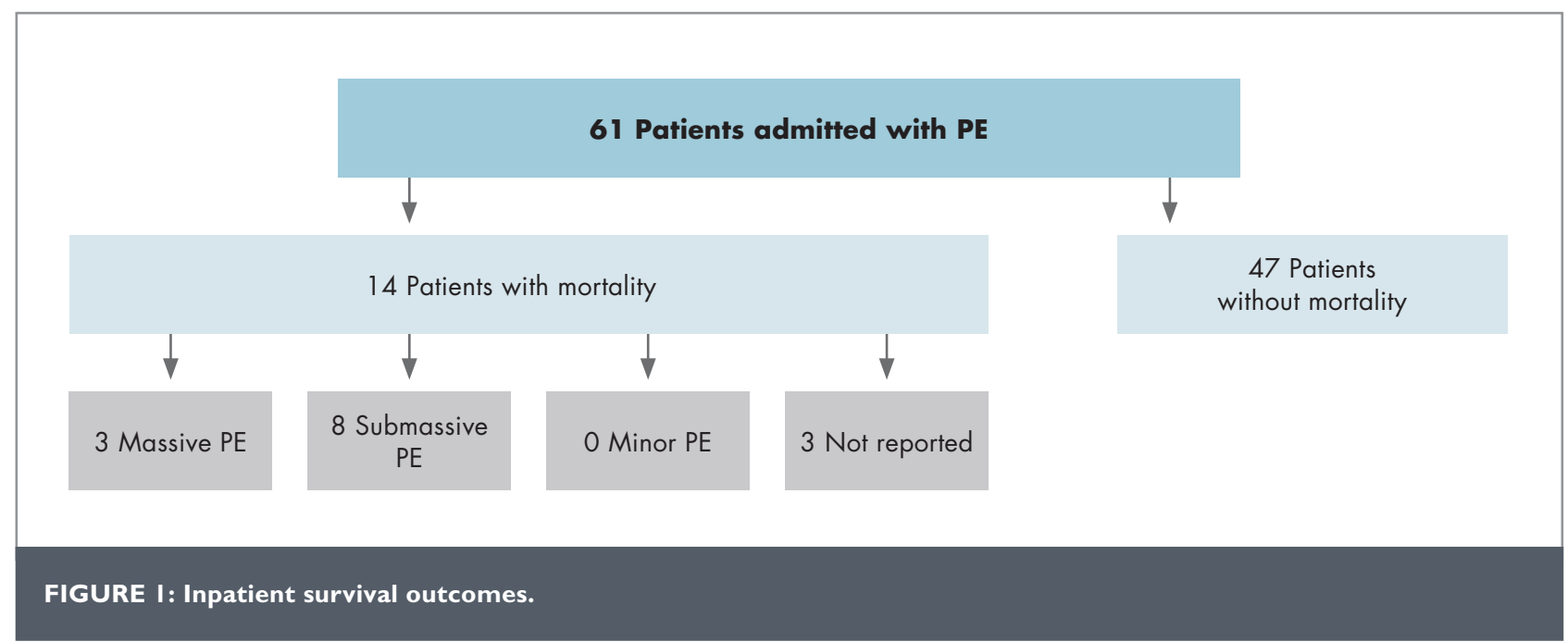

$P E=$ Pulmonary embolism. 
TABLE I: Description of the CS $(\mathbf{N}=61)$.

\begin{tabular}{|c|c|c|c|c|c|}
\hline Characteristic & Sub-category & $\mathrm{n}(\%$ of $\mathrm{N})$ & Characteristic & Sub-category & $\mathrm{n}(\%$ of $\mathrm{N})$ \\
\hline \multirow{2}{*}{ Elderly age (age $\geq 65$ years old) } & Yes & $8(\mid 3.1)$ & \multirow{2}{*}{ Cardiac failure } & Yes & $30(49.2)$ \\
\hline & No & $53(86.9)$ & & No & $31(50.8)$ \\
\hline \multirow[t]{2}{*}{ Gender } & Male & $20(32.8)$ & \multirow[b]{2}{*}{ Stroke } & Yes & $2(3.3)$ \\
\hline & $\begin{array}{c}\text { Female } \\
\text { Yes }\end{array}$ & $\begin{array}{l}41(67.2) \\
45(738)\end{array}$ & & No & $59(96.7)$ \\
\hline African ethnicity & $\begin{array}{l}\text { Yes } \\
\text { No }\end{array}$ & $\begin{array}{l}45(13.8) \\
16(26.2)\end{array}$ & \multirow{2}{*}{ Recent immobilisation* } & Yes & $8(13.1)$ \\
\hline \multirow{2}{*}{ Admitted via ED/CCU } & Yes & $20(32.8)$ & & No & $53(86.9)$ \\
\hline & No & $41(67.2)$ & \multirow{2}{*}{ Recent long-distance travel ${ }^{* *}$} & Yes & $2(3.3)$ \\
\hline \multirow{2}{*}{ Chest pain } & Yes & $25(41.0)$ & & No & $59(96.7)$ \\
\hline & No & $36(59.0)$ & \multirow{2}{*}{ Recent surgery* } & Yes & $10(16.4)$ \\
\hline Dyspnoea & Yes & $53(86.9)$ & & No & $51(83.6)$ \\
\hline \multirow[b]{2}{*}{ Cough } & $\begin{array}{l}\text { No } \\
\text { Yes }\end{array}$ & $\begin{array}{c}8(13.1) \\
23(37.7)\end{array}$ & \multirow{2}{*}{ Recent trauma* } & Yes & $2(3.3)$ \\
\hline & No & $38(62.3)$ & & No & $59(96.7)$ \\
\hline \multirow{2}{*}{ Haemoptysis } & Yes & $10(16.4)$ & \multirow{2}{*}{$\begin{array}{l}\text { Malignancy (solid tumour or } \\
\text { haematological) }\end{array}$} & Yes & $2(3.3)$ \\
\hline & No & $51(83.6)$ & & No & $59(96.7)$ \\
\hline \multirow{2}{*}{ Syncopal events } & Yes & $9(14.7)$ & \multirow[b]{2}{*}{ Tobacco use } & Yes & $6(9.8)$ \\
\hline & No & $52(85.3)$ & & No & $55(90.2)$ \\
\hline \multirow{2}{*}{$\begin{array}{l}\text { Tachypnea } \\
\text { (Respiratory rate }>20 \text { breaths/min) }\end{array}$} & Yes & $29(47.5)$ & \multirow[b]{2}{*}{ Prior PE } & Yes & $5(8.2)$ \\
\hline & $\begin{array}{l}\text { No } \\
\text { Yes }\end{array}$ & $\begin{array}{l}32(52.5) \\
26(42.6)\end{array}$ & & No & $56(91.8)$ \\
\hline Tachycardia (heart rate $>100$ beats/min) & No & $35(57.4)$ & \multirow{2}{*}{ Prior DVT } & Yes & $7(11.5)$ \\
\hline \multirow{2}{*}{ Cyanosis } & Yes & $3(4.9)$ & & No & $54(88.5)$ \\
\hline & No & $58(95.1)$ & & Yes & $12(19.7)$ \\
\hline \multirow{2}{*}{ Pyrexia (temperature $>38.5^{\circ} \mathrm{C}$ ) } & Yes & $2(3.3)$ & Current DVI & No & $49(80.3)$ \\
\hline & No & $59(96.7)$ & & Yes & $0(0.0)$ \\
\hline Lower limb swelling/pain & $\begin{array}{l}\text { Yes } \\
\text { No }\end{array}$ & $\begin{array}{l}23(3 / .1) \\
38(62.3)\end{array}$ & Pregnancy & No & $61(100.0)$ \\
\hline & $\leq 95 \%$ & $17(27.9)$ & Hormonal the 5 & Yes & I ( 1.6$)$ \\
\hline$U_{2}$ saturation (as per pulse oximetry) & $>95 \%$ & $44(72.1)$ & t & No & $60(98.4)$ \\
\hline Abnormal pO ( $\mathrm{O}$ outside & Yes & $21(34.4)$ & & Yes & $17(27.9)$ \\
\hline $\begin{array}{l}\text { Abnormal } \mathrm{pO}_{2}\left(\mathrm{pO}_{2} \text { outside }\right. \\
80-100 \mathrm{mmHg})\end{array}$ & No & $3(4.9)$ & Obesity (body mass index $>30 \mathrm{~kg} / \mathrm{m}^{2}$ ) & No & $14(23.0)$ \\
\hline & Not reported & $37(60.7)$ & & Not reported & $30(49.1)$ \\
\hline Supplemental $\mathrm{O}_{2}$ & Yes & $31(50.8)$ & & Yes & $17(27.9)$ \\
\hline & $\begin{array}{l}\text { No } \\
\text { Yes }\end{array}$ & $\begin{array}{l}30(49.2) \\
5(8.2)\end{array}$ & HIV & No & $44(72.1)$ \\
\hline Mechanical ventilation & No & $56(91.8)$ & & Yes & $8(13.1)$ \\
\hline & Hypotensive & $5(8.2)$ & Prior tudercuiosis & No & $53(86.9)$ \\
\hline & $(\leq 90 \mathrm{mmHg})$ & & & Yes & $3(4.9)$ \\
\hline Systolic blood pressure on admission & $\begin{array}{l}\text { Normotensive } \\
(91-139 \mathrm{mmHg})\end{array}$ & $45(73.8)$ & Current tuberculosis & No & $58(95.1)$ \\
\hline & Hypertensive & & & Massive & $5(8.2)$ \\
\hline & $(\geq 140 \mathrm{mmHg})$ & $11(18.0)$ & & Submassive & $38(62.3)$ \\
\hline & $\begin{array}{c}\text { >99th percentile } \\
\text { URL }\end{array}$ & $31(50.8)$ & PE classification & Minor & $5(8.2)$ \\
\hline D-dimer & $\leq 99$ th & & & Not reported & $13(21.3)$ \\
\hline & percentile URL & $3(4.9)$ & Empoloctomm & Yes & $7(\mid 1.5)$ \\
\hline & Not reported & $37(44.3)$ & Emoorectomy & No & $54(88.5)$ \\
\hline & >99th percentile & $14(23.0)$ & & Yes & $15(24.6)$ \\
\hline & $\begin{array}{l}\text { URL } \\
<99+h\end{array}$ & & Thrombolysis & No & $46(75.4)$ \\
\hline Iroponın & $\begin{array}{l}\text { percentile URL } \\
\text { perth }\end{array}$ & $24(39.3)$ & Anticoarulation & Yes & $58(95.1)$ \\
\hline & Not reported & $23(37.7)$ & & No & $3(4.9)$ \\
\hline
\end{tabular}

$\mathrm{CS}=$ Case series, N/A = Not applicable, ED = Emergency department, CCU = Critical care unit, NYHA = New York Heart Association, URL $=$ Upper reference limit, PE $=$ Pulmonary embolism, DVT $=$ Deep vein thrombosis. "Within the last 4 weeks, ${ }^{* 2}$ Duration $>4$ hours within the last 4 weeks. 
6/14 (42.9\%) patients, respectively. The most common presenting clinical signs were tachycardia (12/14 patients, 85.7\%) and tachypnea ( $9 / 14$ patients, $64.3 \%$ ). Most patients who died were haemodynamically stable on admission (9/14, 64.3\%). D-dimer and troponin were elevated in 7//4 (50.0\%) and 4/14 (28.6\%) patients who died. The most common PE risk factors in patients who died were cardiac failure $(7 / 14,50.0 \%)$ and obesity $(4 / 14,28.6 \%)$. In patients who died, 85.7\% (12/14) underwent anticoagulation therapy, 28.6\% (4/14) underwent embolectomy, and 14.3\% (2//4) underwent thrombolysis.

\section{DISCUSSION}

There are only a few published CS of VTE from SA settings. ${ }^{(9,11)}$ These CS are predominantly comprised of patients with DVT. Our CS differs from these in that we report on a much larger CS of SA patients with PE. We identified 6I cases who were admitted for PE at our institution over a 5-year period. Our findings are in line with a previous report on the rarity of PErelated admissions at SA tertiary-level hospitals. (II)

Our CS was of similar age to that reported in the SA study of Goldstein and Wu. (I) However, our CS was younger than that reported for PE in developed countries, such as the United States. (12) The younger age of SA patients with VTE (when compared with CS in developed countries) can most likely be attributed to the high HIV prevalence in SA, and the HIVassociated coagulopathy in these younger patients. (II) Most of our CS was of black African ethnicity and female. This is in keeping with existing evidence from both SA and overseas settings suggesting a higher incidence of VTE in persons of black African ethnicity and in women. ${ }^{(13,14)}$ The basis for the higher incidence of VTE among persons of black African ethnicity appears to be genetic, ${ }^{(13)}$ while the formation of larger platelet aggregates in women has been proposed as an explanation for the higher incidence of VTE in this group. ${ }^{(14)}$

The SA study of Goldstein and Wu did not report on the signs and symptoms of PE.(I) The most common clinical symptoms of PE in our CS were dyspnoea and chest pain, while the most common clinical signs in our CS were tachypnea and tachycardia. Our findings for PE symptoms/signs are similar to those reported in the overseas literature, in that tachypnea and tachycardia are reported as common clinical signs of PE. ${ }^{(4,15)}$ However, the frequency of these reported symptoms/ signs appears to differ between SA and overseas settings. For instance, we report a higher frequency of dyspnoea and a lower frequency of chest pain when compared with overseas settings. ${ }^{(4,15)}$ With regard to PE signs, we report a lower frequency of tachypnea, but a higher frequency of tachycardia when compared with overseas settings. ${ }^{(4,15)}$ Some clinical symp- toms/signs are included in clinical prediction rules for PE. Therefore, it is possible that clinical prediction scores derived from studies performed in other countries may not be applicable in a SA setting. This might necessitate the development of setting-specific clinical prediction rules for PE.

The most common PE risk factors in our CS were cardiac failure and obesity. Our findings are very different from those of Goldstein and Wu, who reported HIV and tuberculosis to be the most common risk factors in SA patients with VTE. ${ }^{(1)}$ It is possible that the preponderance of cases with DVT in the study of Goldstein and Wu might be an explanation for this difference in findings - as both HIV and tuberculosis were found to be the most common risk factors for DVT in another SA study. ${ }^{(9)}$ In overseas settings, obesity and a history of DVT are the most common PE risk factors, with cardiac failure only present in a small proportion of patients. ${ }^{(12)}$ Therefore, we once again demonstrate some differences in PE between SA and overseas settings. Again, this would also have important diagnostic implications in SA settings, with comorbid risk factors also contributing to overseas clinical prediction rules. ${ }^{(16)}$

The PE population in overseas settings is comprised of patients with massive PE, submassive PE, and minor PE in the following proportions: $5.0 \%, 40.0 \%$ and $55.0 \%$, respectively. ${ }^{(17)}$ Most patients in our CS presented with submassive PE, with massive PE and minor PE occurring less frequently. This is in keeping with the overseas literature. (17) Almost two-thirds of our CS were classified as having submassive PE, with less than 1 in 10 patients classified as having massive PE according to currently accepted definitions, which are based on the presence/absence of haemodynamic instability and cardiac dysfunction/injury. ${ }^{(10)}$ The presence of haemodynamic instability is often a proxy for the degree of occlusion caused by a PE in the pulmonary circulation. ${ }^{(10)}$ Our CS suggests that most patients presenting with a PE in our setting do not have more severe manifestations of PE with associated haemodynamic instability. This is an important finding that requires confirmation in a prospective trial.

Inpatient mortality in our CS was high, even though treatment was administered. This agrees with findings from overseas studies, which also report high mortality in patients with PE.(18-21) Another important finding of our CS, was that the majority of deaths were in patients who had submassive PE (i.e. haemodynamically stable patients). Our findings suggest that in addition to PE with haemodynamic instability (i.e. massive PE), which has traditionally been considered to account for most inpatient deaths in overseas settings, ${ }^{(17)}$ PE in haemodynamically stable patients might be of concern in SA settings. Haemodynamically stable patients with PE in our setting are potentially 
salvageable, and our findings suggest that they should be considered for more aggressive management. As in overseas settings, ${ }^{(10)}$ anticoagulation therapy formed the backbone of PE treatment in SA patients. Also in keeping with overseas management practices, intervention by thrombolysis or embolectomy was only performed when there was a relevant indication to perform either of these interventions. ${ }^{(10,22)}$

A limitation of our CS is that our modest sample size prevented us from performing further statistical investigations of characteristics associated with inpatient mortality. Another limitation of our CS is that it was from a single, tertiary-level healthcare facility. Therefore, our findings might not be applicable to SA patients with PE attending lower-level healthcare facilities. We chose to include only patients who were admitted with a primary diagnosis of PE (and not patients who were existing inpatients) in our CS. This might have introduced selection bias into the research. Due to the retrospective nature of this CS, there might have been under-reporting of some PE symptoms/signs. Another potential limitation of our CS is that the data capture of ICD primary diagnosis codes might have been incorrect, and there might have been some admissions for PE that were missed. Data were missing for some characteristics; however, we did not exclude patients with missing data from our analysis and accounted for missing data with the "not reported" category. Finally, we only report on inpatient outcomes and do not report patient outcomes following discharge from hospital. Large, multicentre, prospective studies are required to address the afore-mentioned limitations.

\section{CONCLUSION}

We provide a report of PE in SA patients. There were differences in PE presentation and risk factors between SA and overseas settings. Some clinical symptoms/signs and risk factors are included in clinical prediction rules for PE that were derived in overseas settings. If there are differences in PE clinical symptoms/signs and risk factors between SA and overseas populations, then overseas clinical prediction rules might be inappropriate for application in SA settings. Setting-specific clinical prediction rules for PE might be required. Inpatient mortality in SA patients with PE was high, even when treatment was administered. Most patients who died had submassive PE. As patients with submassive PE are haemodynamically stable, they are potentially salvageable. These patients should be considered for more aggressive management. Further research is required to confirm our findings, as well as to address the limitations of our research.

\section{REFERENCES}

I. Konstantinides SV, Barco S, Lankeit M, et al. Management of pulmonary embolism: An update. J Am Coll Cardiol 2016;67:976-990.

2. Belohlavek J, Dytrych V, Linhart A. Pulmonary embolism, part I: Epidemiology, risk factors and risk stratification, pathophysiology, clinical presentation, diagnosis and nonthrombotic pulmonary embolism. Exp Clin Cardiol 2013:18:129-138.

3. Calder KK, Herbert M, Henderson SO. The mortality of untreated pulmonary embolism in emergency department patients. Ann Emerg Med 2005: 45:302-310.

4. Kranidis Al, Triantafyllou KA, Manolis AS. Pulmonary embolism: Clinical features and diagnosis. Hospital Chronicles 2006; 1:69-73.

5. Tarbox AK, Swaroop M. Pulmonary embolism. Int J Crit IIIn Inj Sci 2013; 3:69-72.

6. Goolam-Mahomed A. Pulmonary thrombo-embolic disease. Continuing Medical Education 2013;31:335-338.

7. Arboix A, Alio J. Cardioembolic stroke: Clinical features, specific cardiac disorders and prognosis. Curr Cardiol Rev 20 I0;6:150-161.

8. Shibata T, Kawakami S, Noguchi T, et al. Prevalence, clinical features, and prognosis of acute myocardial infarction attributable to coronary artery embolism. Circulation 2015; 132:241-250

9. Awolesi D, Naidoo M, Cassimijee $\mathrm{MH}$. The profile and frequency of known risk factors or comorbidities for deep vein thrombosis in an urban district hospital in KwaZulu-Natal. South Afr J HIV Med 201 6; 17:425.

10. Jaff MR, McMurtry MS, Archer SL, et al. Management of massive and submassive pulmonary embolism, iliofemoral deep vein thrombosis, and chronic thromboembolic pulmonary hypertension: A scientific statement from the American Heart Association. Circulation 201 1; 123:1788-1830.

II. Goldstein LN, Wu M-T. A I year audit of patients with venous thromboembolism presenting to a tertiary hospital in Johannesburg, South Africa. African Journal of Emergency Medicine 2018;8:12-15.

12. Anderson FA, Wheeler HB. Physician practices in the management of venous thromboembolism: A community-wide survey. J Vasc Surg 1992; |6:707-7|4.

13. Heit JA, Beckman MG, Bockenstedt PL, et al. Comparison of characteristics from White- and Black-Americans with venous thromboembolism: A crosssectional study. Am J Hematol 20 I 0;85:467-47| .

14. Bailey AL, Scantlebury DC, Smyth SS. Thrombosis and antithrombotic therapy in women. Arterioscler Thromb Vasc Biol 2009;29:284-288.

15. Stein PD, Beemath A, Matta F, et al. Clinical characteristics of patients with acute pulmonary embolism: Data from PIOPED II. Am J Med 2007; 120:87|-879

16. Wells PS, Ginsberg JS, Anderson DR, et al. Use of a clinical model for safe management of patients with suspected pulmonary embolism. Ann Intern Med 1998; 129:997-1005.

17. Goldhaber SZ, Visani L, De Rosa M. Acute pulmonary embolism: Clinical outcomes in the International Cooperative Pulmonary Embolism Registry (ICOPER). Lancet 1999;353:1386-1389.

18. Coleman Cl, Kohn CG, Crivera C, et al. Validation of the multivariable Inhospital Mortality for PulmonAry embolism using Claims daTa (IMPACT) prediction rule within an all-payer inpatient administrative claims database. BMJ Open 2015;5:e00925।.

19. Smith SB, Geske JB, Kathuria P, et al. Analysis of national trends in admissions for pulmonary embolism. Chest 2016; 150:35-45

20. Gouveia M, Pinheiro L, Costa J, et al. Pulmonary embolism in Portugal: Epidemiology and in-hospital mortality. Acta Med Port 2016;29:432-440,

21. Agnelli G, Becattini C. Acute pulmonary embolism. N Engl J Med 2010; 363:266-274.

22. Liew A, Malley T. Tough decisions in pulmonary embolism: Thrombolysis or embolectomy? Oxf Med Case Reports 2016;2016:omw070

\section{Conflict of interest: none declared.}

